Sādhanā Vol. 39, Part 6, December 2014, pp. 1295-1310. (C) Indian Academy of Sciences

\title{
High performance predictive current control of a three phase VSI: An experimental assessment
}

\author{
VIKAS KUMAR*, PRERNA GAUR and A P MITTAL \\ Division of Instrumentation and Control Engineering, Netaji Subhas \\ Institute of Technology, New Delhi 110 078, India \\ e-mail: sainivika@gmail.com; prernagaur@gmail.com; mittalap@gmail.com
}

MS received 10 February 2014; revised 13 May 2014; accepted 24 August 2014

\begin{abstract}
Delay has a significant role to play in the implementation of the predictive current control scheme as large amount of calculations are involved. Compensating delay in the predictive current controller design can lead to an improved load current total harmonic distortion (THD) and also an increased switching frequency. Minimization of switching frequency while maintaining the lower value of load current THD requires multiple objective optimization which is achieved by optimizing a single objective function, constructed using weighting factors as a linear combination of individual objective function. The effect of weighting factor on the switching frequency minimization and the current tracking error with delay compensation for the two level voltage source inverter (VSI) are investigated in this paper. The outcomes of the predictive current control using an optimized weighting factor which is calculated using branch and bound algorithm with the delay compensation are compared with the PWM based current control scheme. The experimental tests are conducted on a $2.2 \mathrm{~kW}$ VSI to verify the simulation observations.
\end{abstract}

Keywords. Voltage source inverter; two level inverter; predictive current control; weighting factor; switching frequency.

\section{Introduction}

The three phase voltage source inverters (VSI) are predominantly used in domestic and industrial applications such as AC motor drives, AC uninterruptible power supplies, induction heating, AC power supply from the battery and active harmonic filters (Mohan et al 1995; Bose 2002). The quality of the output voltage generated by VSI depends on the control scheme used. The main aim of the control scheme is to synthesize the output voltage as close as possible to the sinusoidal waveforms. Many control schemes are developed for the total harmonic reduction and switching loss minimization (Holtz 1994). Among the various control schemes available for power converters hysteresis based control and linear control combined with a modulation stage

*For correspondence 
are well-established and simple to implement. The variable frequency requirement for hysteresis based control causes resonance problems which further leads for bulky and expensive filters. Using linear control scheme, it is very challenging to meet the multiple control objectives for appropriate control demands (Shu et al 2007; Saribulut et al 2012; Mondal et al 2003; Dordevic et al 2013). The continuous development in the processing capabilities of digital signal processors has enabled the implementation of the complex control techniques which were difficult to implement earlier and now there is a strong trend towards the fully digital control of the power converters and electrical drives. The finite state model predictive control (FS-MPC) has emerged as a powerful alternative to the control of power converters and electrical drives (Abu-Rub et al 2004) due to its fast dynamic response, easy inclusion of system nonlinearity, precise current control and multi-objective optimization. The FS-MPC for current control of a a three phase VSI has been implemented by (Rodriguez et al 2007) by taking into account all the switching states of the inverter. Since then the FS-MPC technique has been widely explored by the researchers and the academicians for the control of the power converters and the electrical drives (Judewicz et al 2013; Kouro et al 2009). The two level inverter contains seven distinct switching states viz. six distinct states and two zero states. Conventionally, for reference current tracking control in a two level VSI, the objective function is evaluated for seven distinct switching states and the optimized switching state is one which minimizes the given objective function. As implementation of predictive control requires prediction of the future states and online optimization to calculate the optimized switching state, the algorithm can be computationally demanding and the delay has a significant role to play in the performance of the predictive controller. It can deteriorate the performance if not considered in the design. (Cortes et al 2012) have shown that THD of the load current is improved if delay is properly considered in the design. However, the switching frequency almost got doubled (Fischer et al 2014; Preindl et al 2011). The possible solution to reduce the switching frequency and to maintain the low THD level in the load current waveform can be the multi-objective optimization (Cortes et al 2009). The multiple objectives in a model predictive control can be optimized using weighting factors as a linear combination of individual objective function.

In this paper, the effect of multiple objective optimizations i.e., reference current tracking and the switching frequency minimization on the performance of the two level inverter by incorporating all possible switching states of the inverter is investigated. The predictive current control algorithm is implemented for two cases namely, (i) without delay compensation and (ii) with delay compensation for different values of weighting factor together with an optimized weighting factor calculated using branch and bound (Cortes et al 2009) algorithm. The simulation results obtained from the predictive current control with delay compensation schemes are compared with the PWM based control scheme. The experimental tests are conducted to verify the simulation outcomes.

The rest of the paper is organized as follows: The modelling of the inverter and the three phase load is presented in section 2. In section 3, the predictive current control strategy with delay compensation and PWM based current control schemes are discussed. The details of the experimental set-up are given in section 4 . The simulation and experimental results are presented in section 5 and the conclusions are given in section 6.

\section{Modelling of the inverter and the load}

The three phase RLE type load is connected to the VSI as shown in figure 1. The dynamics of the inverter and load are described by the differential equation (Rodriguez \& Cortes 2012): 


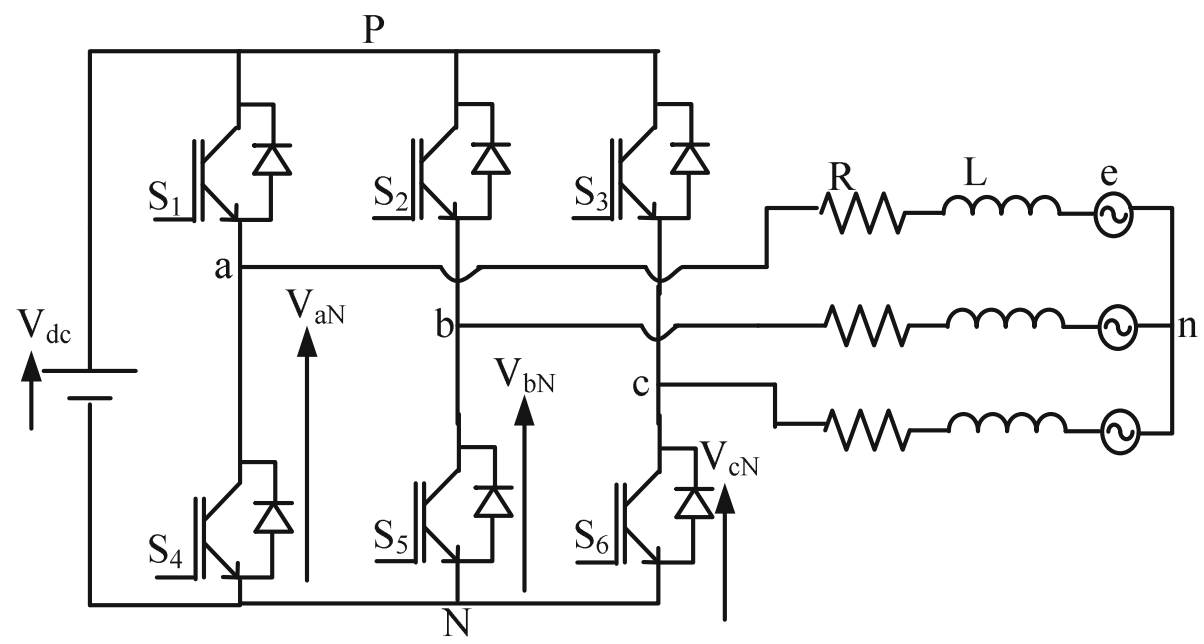

Figure 1. Two level voltage source inverter with R-L-E load.

The two switches in each inverter leg operate in a complementary mode in order to avoid short circuiting of the DC source. The output phase to neutral voltages $V_{a n}, V_{b n}, V_{c n}$ of the three phase inverter is given as follows (Bose 2002):

$$
\left.\begin{array}{l}
V_{a n}=S_{a} * V_{d c} \\
V_{b n}=S_{b} * V_{d c} \\
V_{c n}=S_{c} * V_{d c}
\end{array}\right),
$$

where

$$
\begin{aligned}
& s_{a}=\left\{\begin{array}{l}
1 \text { if } S_{1} \text { is on and } S_{4} \text { is off } \\
0 \text { if } S_{1} \text { is off and } S_{4} \text { is on }
\end{array}\right. \\
& S_{b}=\left\{\begin{array}{l}
1 \text { if } S_{2} \text { is on and } S_{5} \text { is off } \\
0 \text { if } S_{2} \text { is off and } S_{5} \text { is on }
\end{array}\right. \\
& S_{c}=\left\{\begin{array}{l}
1 \text { if } S_{3} \text { is on and } S_{6} \text { is off } \\
0 \text { if } S_{4} \text { is off and } S_{6} \text { is on. }
\end{array}\right.
\end{aligned}
$$

Considering $a=e^{j 2 \pi / 3}$ as unit vector, representing the $120^{\circ}$ phase displacement between the phases and the space vector, the output voltage of the inverter can be written as:

$$
\mathrm{u}=\frac{2}{3}\left(\mathrm{v}_{\mathrm{an}}+\mathrm{av}_{\mathrm{bn}}+\mathrm{a}^{2} \mathrm{v}_{\mathrm{cn}}\right)
$$

using (5) the output voltage of the inverter for the eight possible switching states of the inverter can be determined.

The three phase load and the dynamics is described by the KVL equation

$$
u=R i+L \frac{d i}{d t}+e,
$$


where $\mathrm{u}$ is the inverter output voltage, $\mathrm{R}$ is the load resistance, $\mathrm{L}$ is the load impedance, $\mathrm{e}$ is the back emf and $\mathrm{i}$ is the load current. The load model can be expressed in two phase stationary frame using Clarke's transformation matrix (7)

$$
\left[\begin{array}{l}
\alpha \\
\beta
\end{array}\right]=\left[\begin{array}{c}
2 / 3-1 / 3-1 / 3 \\
0 \sqrt{3} / 3-\sqrt{3} / 3
\end{array}\right]\left[\begin{array}{l}
a \\
b \\
c
\end{array}\right]
$$

where $\mathrm{a}, \mathrm{b}$ and $\mathrm{c}$ are the phase variables of voltage or current and $\alpha, \beta$ are the vectorial variables.

Using (7), (6) can be written as:

$$
u_{\alpha, \beta}=R i_{\alpha, \beta}+L \frac{d i_{\alpha, \beta}}{d t} e_{\alpha, \beta}
$$

where $u_{\alpha, \beta}$ is the inverter voltage vector, $i_{\alpha, \beta}$ is the real and imaginary parts of the load current vector and $e_{\alpha, \beta}$ is the real and imaginary parts of the load back emf.

Using forward Euler's approximation di/dt can be written as

$$
\frac{\mathrm{d} i_{\alpha, \beta}}{\mathrm{dt}} \approx \frac{i_{\alpha, \beta}(\mathrm{k}+1)-i_{\alpha, \beta}(\mathrm{k})}{\mathrm{Ts}}
$$

Using (8) and (9), the predicted load current can be rewritten as

$$
\mathrm{i}_{\alpha, \beta}^{\mathrm{P}}(\mathrm{k}+1)=\left(1-\frac{\mathrm{RTs}}{\mathrm{L}}\right)\left(i_{\alpha, \beta}(\mathrm{k})\right)+\frac{\mathrm{Ts}}{\mathrm{L}}\left(u_{\alpha, \beta}(\mathrm{k})-e_{\alpha, \beta}(\mathrm{k})\right),
$$

$e_{\alpha, \beta}(\mathrm{k})$ is the estimated back emf, $\mathrm{i}_{\alpha}^{\mathrm{P}}(\mathrm{k}+1), \mathrm{i}_{\beta}^{\mathrm{P}}(\mathrm{k}+1)$ is the predicted real and imaginary part of the load current vector. Using (10) the load current can be predicted. The real and imaginary parts of the estimated back emf can be predicted using following Eq. (11), which can be derived using (10) as

$$
e_{\alpha, \beta}(k-1)=u_{\alpha, \beta}(k-1)-\frac{L}{T s}\left(i_{\alpha, \beta}(k)\right)-\left(R-\frac{L}{T s}\right)\left(i_{\alpha, \beta}(k-1)\right) .
$$

\section{Current control schemes}

The predictive current control scheme and the PWM based current control schemes are discussed in the following section.

\subsection{Predictive current control scheme}

The schematic of the predictive current control scheme is shown in figure 2. The load currents are measured and are converted into two phases using Clarke's transformation. The current error is calculated between the reference current and the load current. Using the load model as derived in section 2 and the measured load current at the current sampling instant, the value of the load current for the next sampling instant and the load back emf at the current sampling instant for seven possible switching states of the inverter is predicted using (10) and (11), respectively. The 


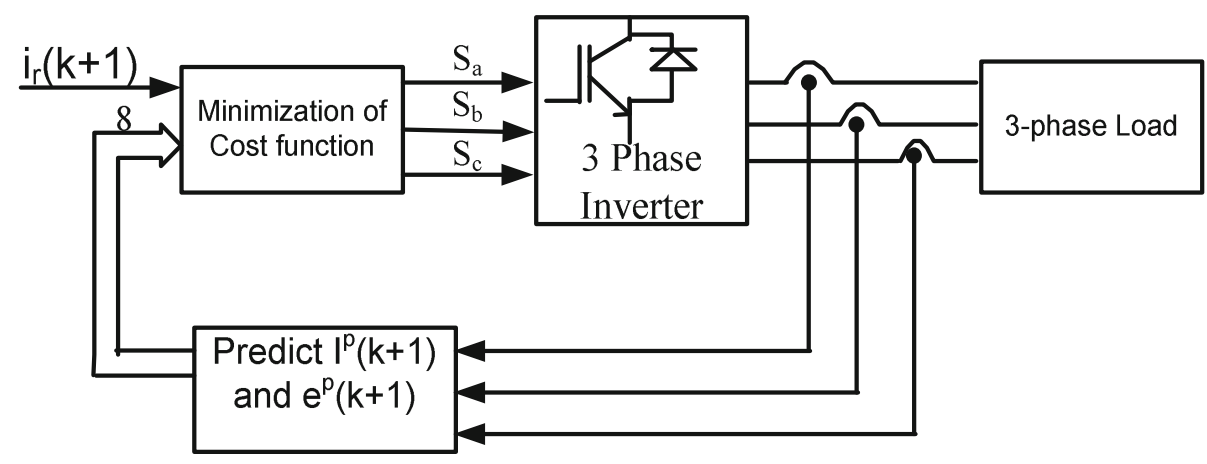

Figure 2. Line diagram for predictive current control.

switching state which minimizes the cost function given by (12) is chosen as the optimized state and is applied at the next sampling instant

$$
g(k+1)=\left|i_{\alpha}^{r}(k+1)-i_{\alpha}^{p}(k+1)\right|+\left|i_{\beta}^{r}(k+1)-i_{\beta}^{p}(k+1)\right| .
$$

For two objective functions i.e., the reference current tracking and the switching frequency minimization the objective function is defined by (13)

$$
g(k+1)=\left|i_{\alpha}^{r}(k+1)-i_{\alpha}^{p}(k+1)\right|+\left|i_{\beta}^{r}(k+1)-i_{\beta}^{p}(k+1)\right|+\lambda_{s} \mathrm{~N}_{s} .
$$

$\mathrm{N}_{s}$ represents the number of switchings involved when changing from the present state to the future state. $\lambda_{s}$ is the weighting factor, used for the relative importance of the switching frequency.

The more the value of the weighting factors, more will be the importance of that particular objective. The value of these weighting factors can be determined through branch and bound algorithm. The branch and bound algorithm is described in the following section.

3.1a Delay compensation: The real time implementation of FS-MPC requires prediction of future states, which requires a large number of calculations, introducing a considerable delay in the actuation. The delay can deteriorate the performance of the predictive current control strategy if not considered in the design. A three phase 2L-VSI contains seven distinct switching states, the predicted current and the cost function is evaluated seven times in one sampling period.

Hence depending upon the sampling frequency and speed of the microprocessor, there is a significant time elapsed between the measurement of the load currents and the application of new switching state. The timing of various tasks is shown in figure 3 .

The timing of different tasks is explained as follows: (i) Apply the new switching state. (ii) Load current measurements. (iii) Back emf estimations. (iv) Load current prediction and selection of optimal switching state. (v) The optimal switching state is applied at $\mathrm{t}=\mathrm{k}+1$ and effect of voltage vector is visible at time $\mathrm{k}+2$. (vi) Current $\mathrm{i}(\mathrm{k}+1)$ is estimated using previously calculated $\mathrm{v}(\mathrm{k})$ and measured current. (vii) Predicted current is calculated for time $\mathrm{t}=\mathrm{k}+2$.

A simple solution to compensate this delay is to take into account the calculation time and apply the selected switching state after the next sampling instant. The predictive current control algorithm with delay and without delay compensation is shown in figures $4 \mathrm{a}$ and b, respectively. 

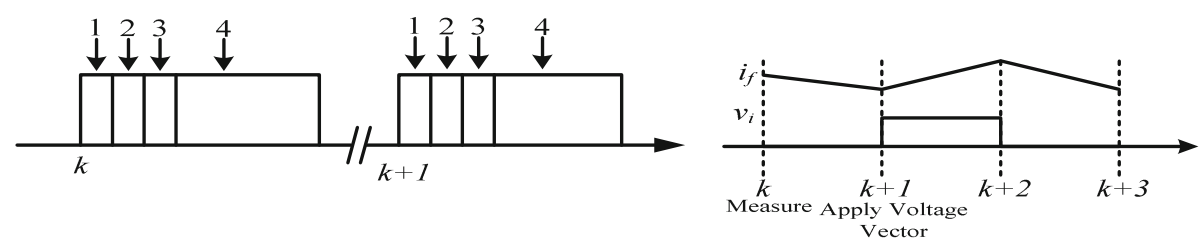

Figure 3. Timing of different tasks.

3.1b Branch and bound algorithm: The AOF or single cost function as given in (13) is used for optimization. The weighting factors are calculated using branch and bound algorithm. The branch and bound algorithm for two objective functions $g_{1}$ and $g_{2}$ are shown in figure 5 . The algorithm starts with the four different values of the weighting factors $\lambda_{1}=0, \lambda_{2}=1, \lambda_{3}=10$ and $\lambda_{4}=100$. The objective function given in (13) is evaluated and for the mentioned values of $\lambda$. Let for $\lambda_{1}$ and $\lambda_{2}$ we get the small numerical value of the cost function $\mathrm{g}$ compared to $\lambda_{3}$ and $\lambda_{4}$.

The $\lambda$ is modified as the average of $\lambda_{1}$ and $\lambda_{2}$ which is 0.5 . The cost function is again evaluated for $\lambda_{1}, \lambda_{2}$ and $\lambda$. Let this time the minimum value lies between $\lambda_{1}$ and $\lambda$ i.e., $0<=\lambda<=0.5$ the $\lambda$ is modified to 0.25 as shown in figure 5 . The procedure is repeated till we get the minimum value of the cost function (Cortes et al 2009).

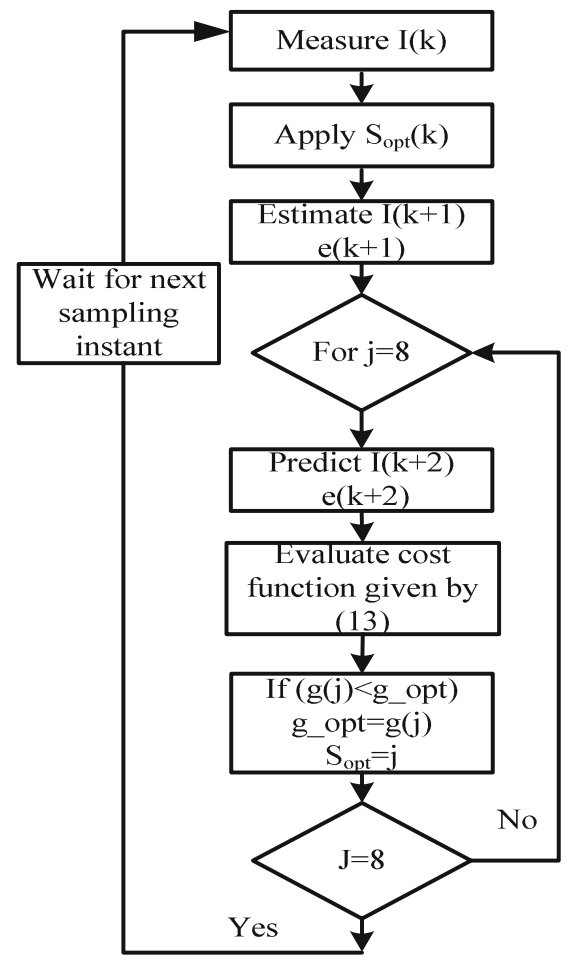

(a)

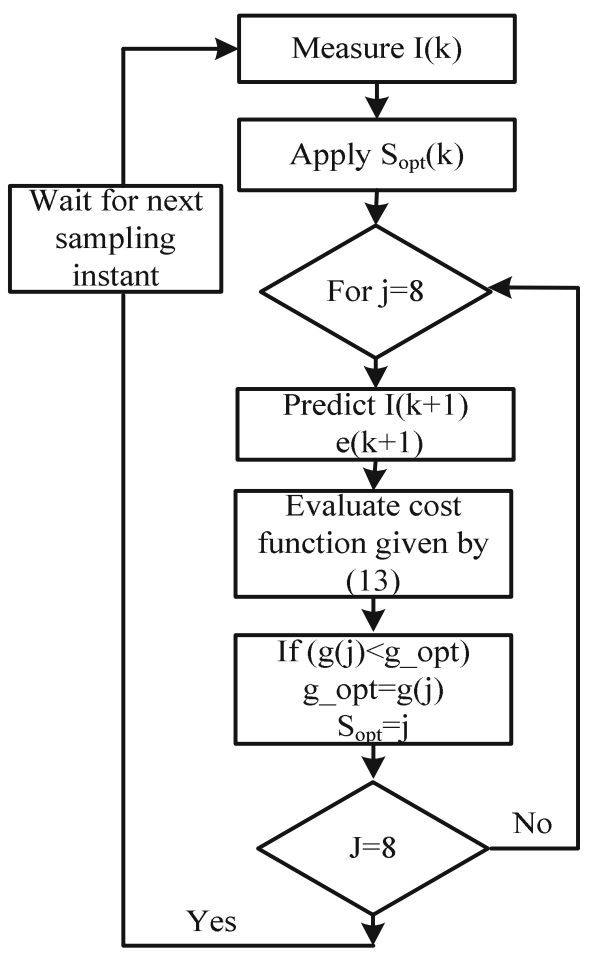

(b)

Figure 4. Predictive current control algorithm (a) with delay compensation, (b) without delay compensation. 


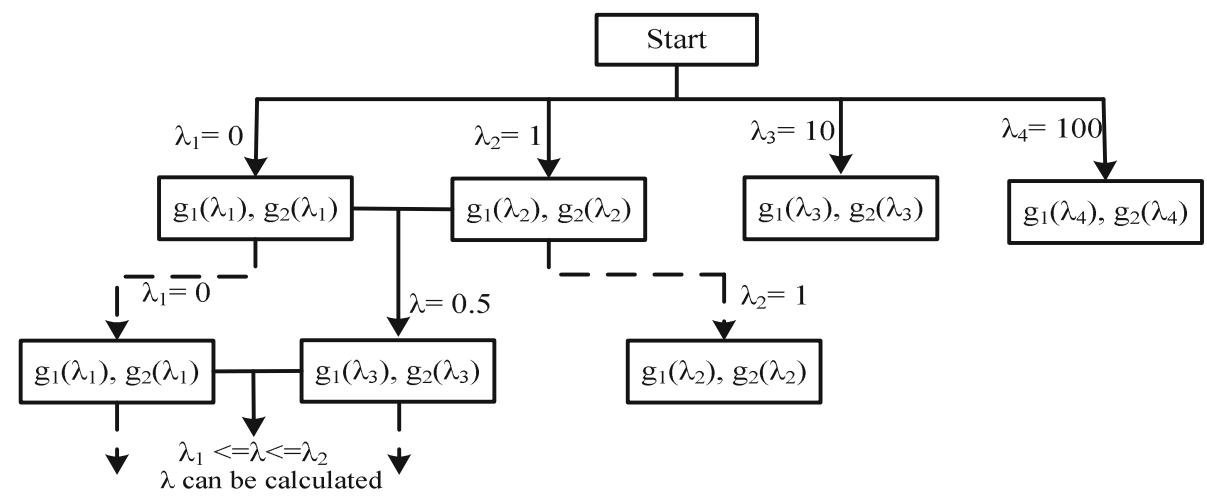

Figure 5. Branch and bound algorithm.

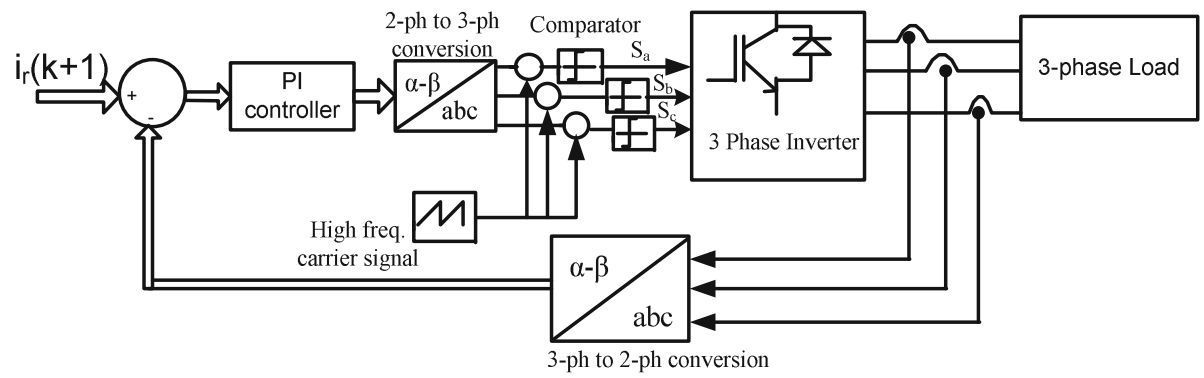

Figure 6. PWM based current control scheme.

\subsection{PWM current control scheme}

The PWM based current control scheme is shown in figure 6. The measured three phase load currents are converted to two phase currents and are then compared to the reference two phase currents. The current error is processed by a PI controller, which is used to generate the reference voltage signal. The reference voltage signal is compared with the triangular carrier wave of high frequency and the output of the comparator is used to control the each inverter leg. The maximum switching frequency in the PWM based method depends on the carrier frequency used. The performance of the control scheme is governed by the tuning of the PI controller. A good steady state response can be obtained from this control scheme.

\section{Experimental set-up}

The real time experiments are carried out with a $3 \Phi$ voltage source inverter in an intelligent power module (IPM) connected to three phase load. The dSPACE (DS-1104) is used for interfacing the IPM that contains the gate drive mechanism, six IGBTs and the protection circuits to the three phase load. The load currents are sensed using Hall effect current sensors (LTS 25-NP) and are acquired through a 12-bit analog to digital converters. The hardware schematic for real time implementation is shown in figure 7 and the snapshot of the experimental set-up is shown in figure 8. The three phase variable inductive load from M/s Powercap Systems; rated at $415 \mathrm{~V}$, 


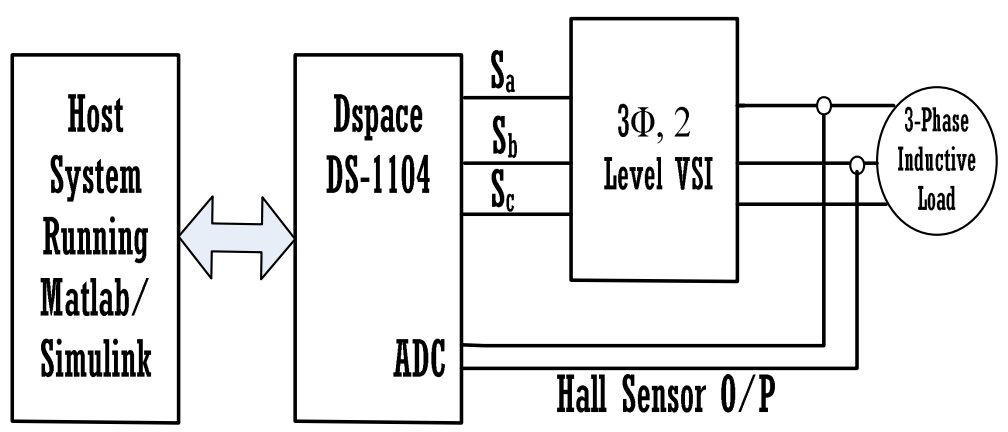

Figure 7. Hardware schematic for real time implementation.

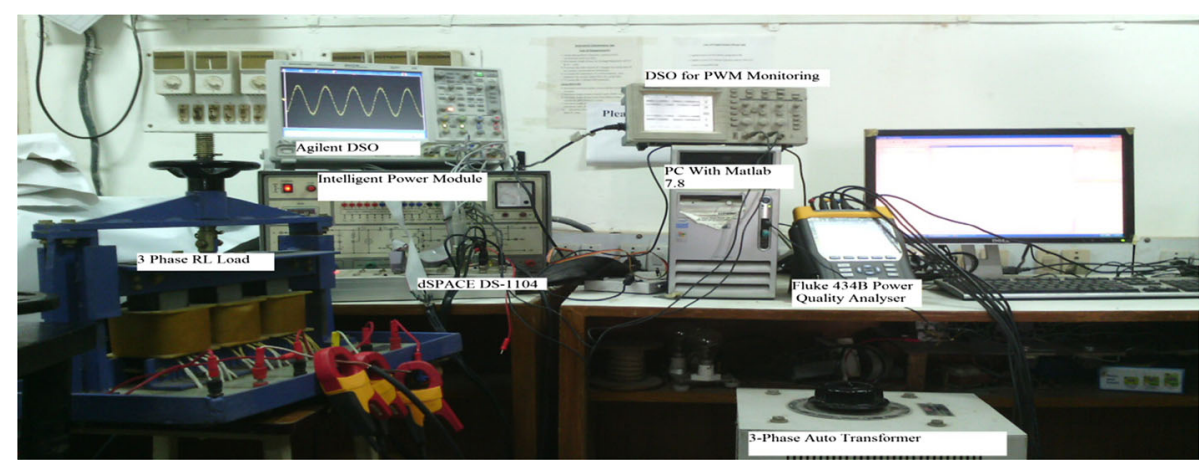

Figure 8. Snapshot of experimental set-up.

0-15 A, $50 \mathrm{~Hz}$ is connected to the IPM module and the load parameters are determined by conducting conventional tests. The load parameters and the rating of the devices are shown in the appendix A.

The three phase output of the auto transformer is connected to the IPM module which contains a 3- $\Phi$ uncontrolled diode bridge rectifier. The rectifier is rated at $(60 \mathrm{~A}, 1200 \mathrm{~V})$. The maximum value of DC link voltage is $750 \mathrm{~V}$. DC link voltage is applied to the $3-\Phi$ IGBT bridge inverter. The PWMs are generated for six IGBTs depending upon the error between the reference current and the measured load current. A dead band of $5 \mu \mathrm{s}$ has been provided between two complementary PWM signals.

\section{Results and discussions}

\subsection{Simulation results}

The discrete time model of the three phase inverter and the load is developed and the computer simulations are carried out using Matlab/Simulink. In order to have a fair comparison between the simulation and experimental results, the same parameters are being used for computer simulations and experimental validations. The load parameters are given in the appendix A. The predictive current control scheme with/without delay compensation and PWM based current control are implemented. The implementation of the delay compensation in the predictive current controlcan be found in Cortes et al (2012). The predictive current control technique is further 

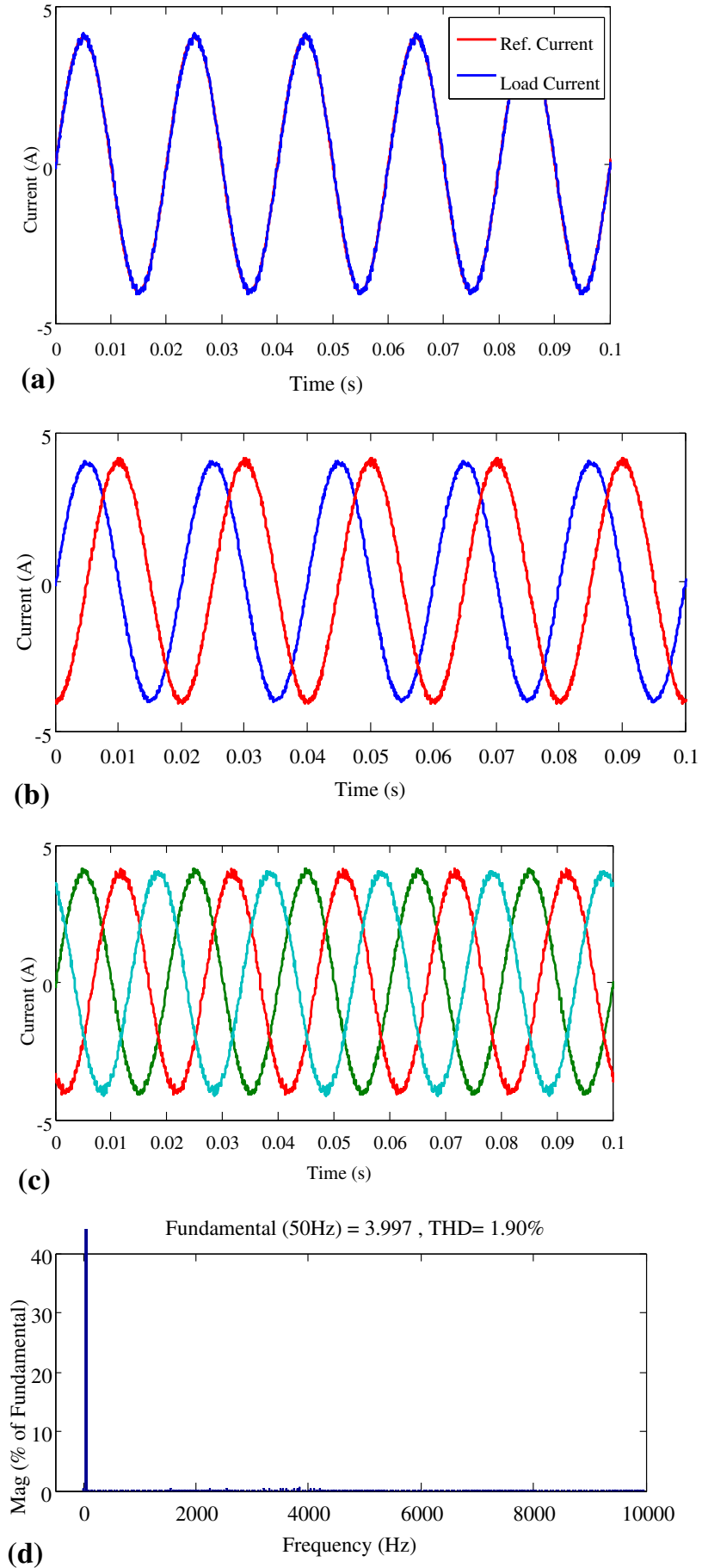

Figure 9. Results of predictive current control with an optimized weighting factor (a) reference current tracking, (b) $\alpha$ (blue line)- $\beta$ (red line) components of current, (c) three phase current and (d) spectrum analysis of load current. 
evaluated for different values of weighting factors. The cost function defined in (13) is evaluated for all possible switching states of the inverter for $\lambda=0,0.01,0.05$ and 0.1 . The optimized value of $\lambda$ is calculated using the branch and bound algorithm. The optimized value of $\lambda$ is 0.05 .

The simulation results of the predictive current control with an optimized weighting factor $\lambda=0.05$ are shown in figures 9 and 10 . The current tracking performance is shown in figure $9 \mathrm{a}$. The calculated mean square error (MSE) for the reference current tracking is 0.0066 . The $\alpha, \beta$ components of load current are decoupled from each other as shown in figure $9 \mathrm{~b}$. The three phase load currents are shown in figure 9c, and the spectrum analysis of the load current is shown in figure 9d, the calculated THD for the load current is $1.90 \%$.

The dynamic performance of the predictive current control is tested by changing the reference current amplitude from $-4 \mathrm{~A}$ to $-2 \mathrm{~A}$, at time $\mathrm{t}=0.035 \mathrm{~s}$. The step response is shown in figure 10a. A good dynamic response is seen as the real component of the load current reaches its reference in very small time. The $\alpha$ and $\beta$ components of load current are decoupled from each other as shown in $10 \mathrm{~b}$.

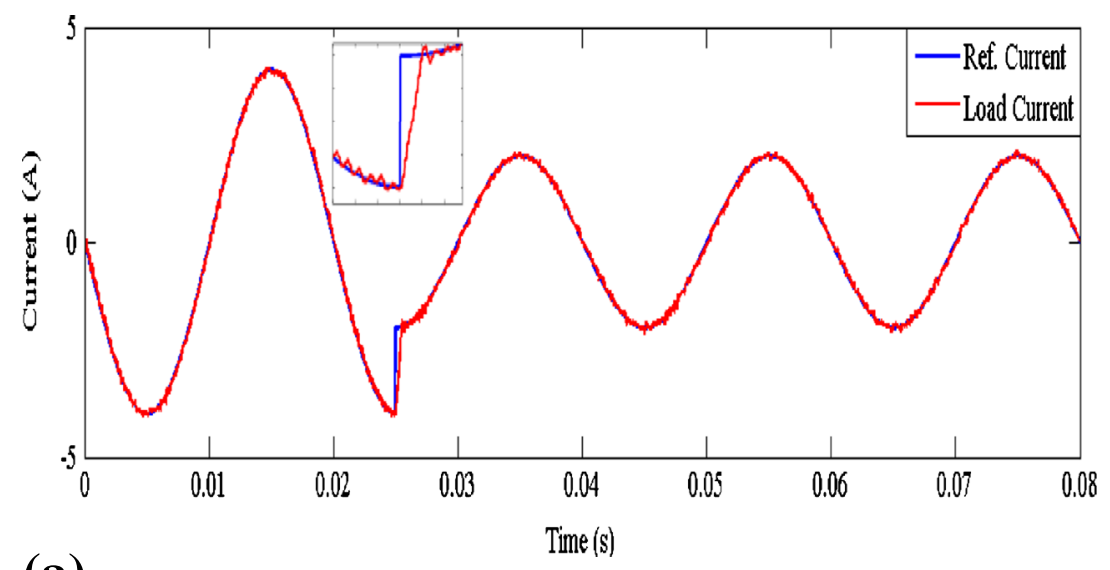

(a)

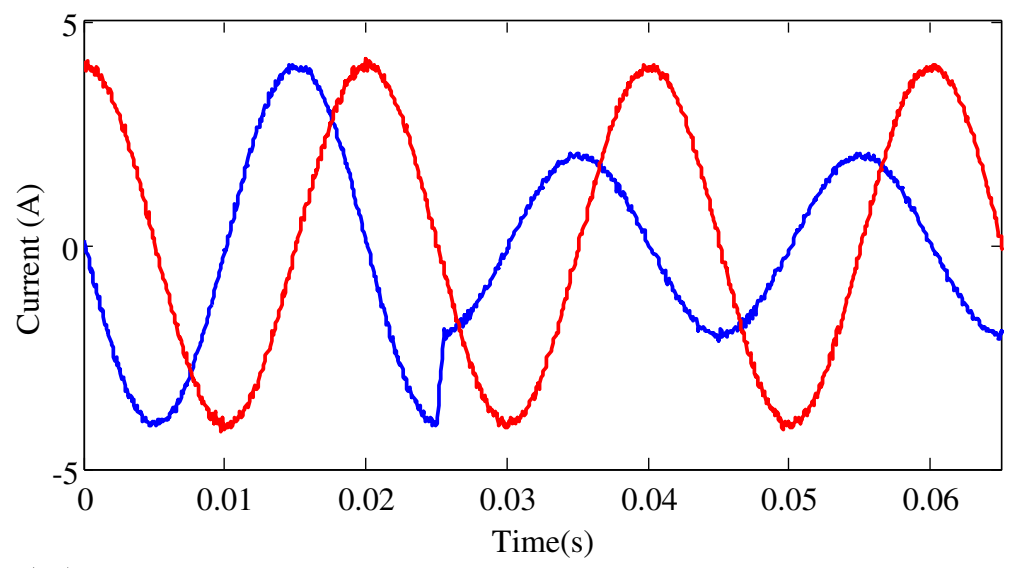

(b)

Figure 10. Results of predictive current control for (a) step change in input reference current current (blue line) measured current (red line) and (b) decoupled $\alpha$ (blue Line)- $\beta$ (red line) current. 


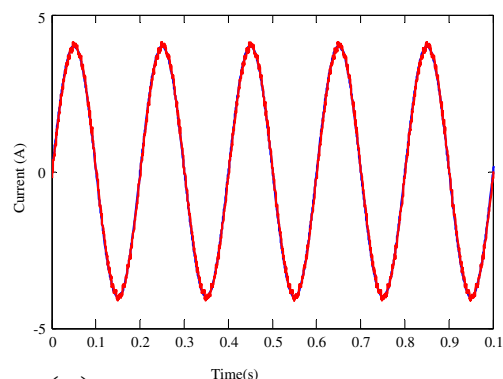

(a)

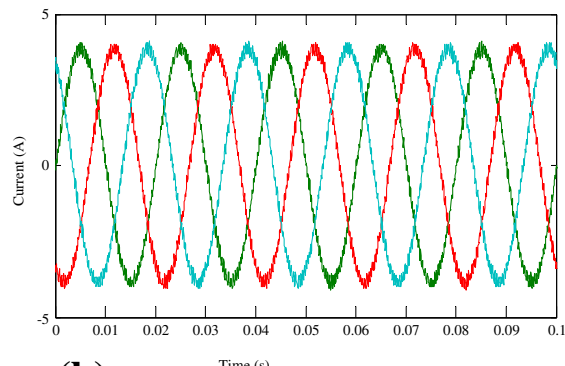

(b)

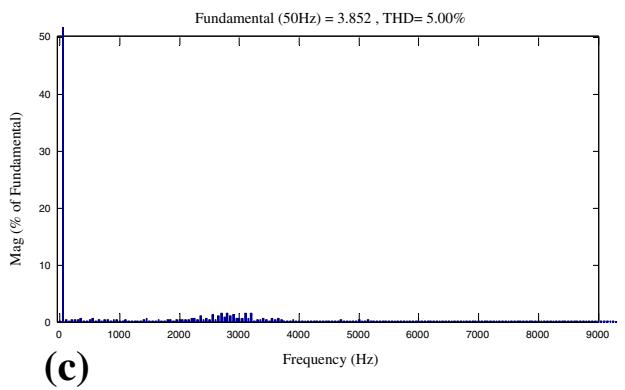

Figure 11. Results of PWM based current control scheme (a) ref. current (blue line) and load current (red line), (b) three phase current and (c) spectrum analysis of load current.

The simulation results of the PWM based current control schemes are shown in figure 11 . The response to a reference current tracking erros is shown in figure $11 \mathrm{a}$, the measured current is shown by red line and the reference current is shown by blue line. The MSE for reference current tracking for PWM based current control scheme is 0.0135 slightly higher as compared to the predictive control scheme. The calculated current THD of the load current is $5 \%$ as shown in figure 11c. The summary of the simulation results is presented in table 1. For predictive current control without delay compensation approach the current tracking MSE is 0.0178, THD of load voltage is $24.52 \%$ and the load current is $4.95 \%$, are on the higher side as compared to the delay compensated approach for $\lambda=0$. Moreover, with the delay compensation approach for $\lambda=0$, the switching frequency is increased to almost 1.8 times. Introducing delay compensation for multiple objective optimizations, the MSE for current tracking, THD of load voltage and load current are the lowest for an optimized weighting factor, $\lambda=0.05$. The switching frequency is reduced to less than half as compared to the case where, $\lambda=0$ and is almost the same as in case of PWM based method.

Table 1. Simulation results of predicted current control techniques.

\begin{tabular}{lcccccc}
\hline & \multicolumn{5}{c}{ Predictive current control } \\
\cline { 2 - 5 } Performance index & Without delay & \multicolumn{4}{c}{ With delay compensation } & \\
\cline { 3 - 6 } & compensation & $\lambda=0$ & $\lambda=0.01$ & $\lambda=0.05$ & $\lambda=0.1$ & PWM \\
\hline Current MSE & 0.0178 & 0.0045 & 0.0049 & 0.0066 & 0.0073 & 0.0135 \\
Voltage THD \% & 24.52 & 28.56 & 28.78 & 27.50 & 31.12 & 38.31 \\
Load current THD \% & 4.95 & 1.73 & 1.86 & 1.90 & 2.2 & 5.00 \\
Average switching frequency & $2.61 \mathrm{kHz}$ & $4.7 \mathrm{kHz}$ & $3.6 \mathrm{kHz}$ & $2.2 \mathrm{kHz}$ & $1.09 \mathrm{kHz}$ & $\sim 2 \mathrm{k} \mathrm{Hz}$ \\
\hline
\end{tabular}




\subsection{Experimental results}

The real time experiments are carried out for using the available hardware and dSPACE (DS1104). The predictive current control of two level VSI is investigated for the weighting factors as considered in simulink implementations. The experimental results of the predictive current control strategy for an optimized weighting factor are shown in figure 12. The reference current tracking response is shown in figure 12a, the yellow line shows the measured current and the green line shows the reference current. The calculated tracking error is 0.0088 .

The $\alpha-\beta$ components of load currents of load current are decoupled from each other as shown in figure $12 \mathrm{~b}$. The three phase load current is shown in figure $12 \mathrm{c}$ and the calculated
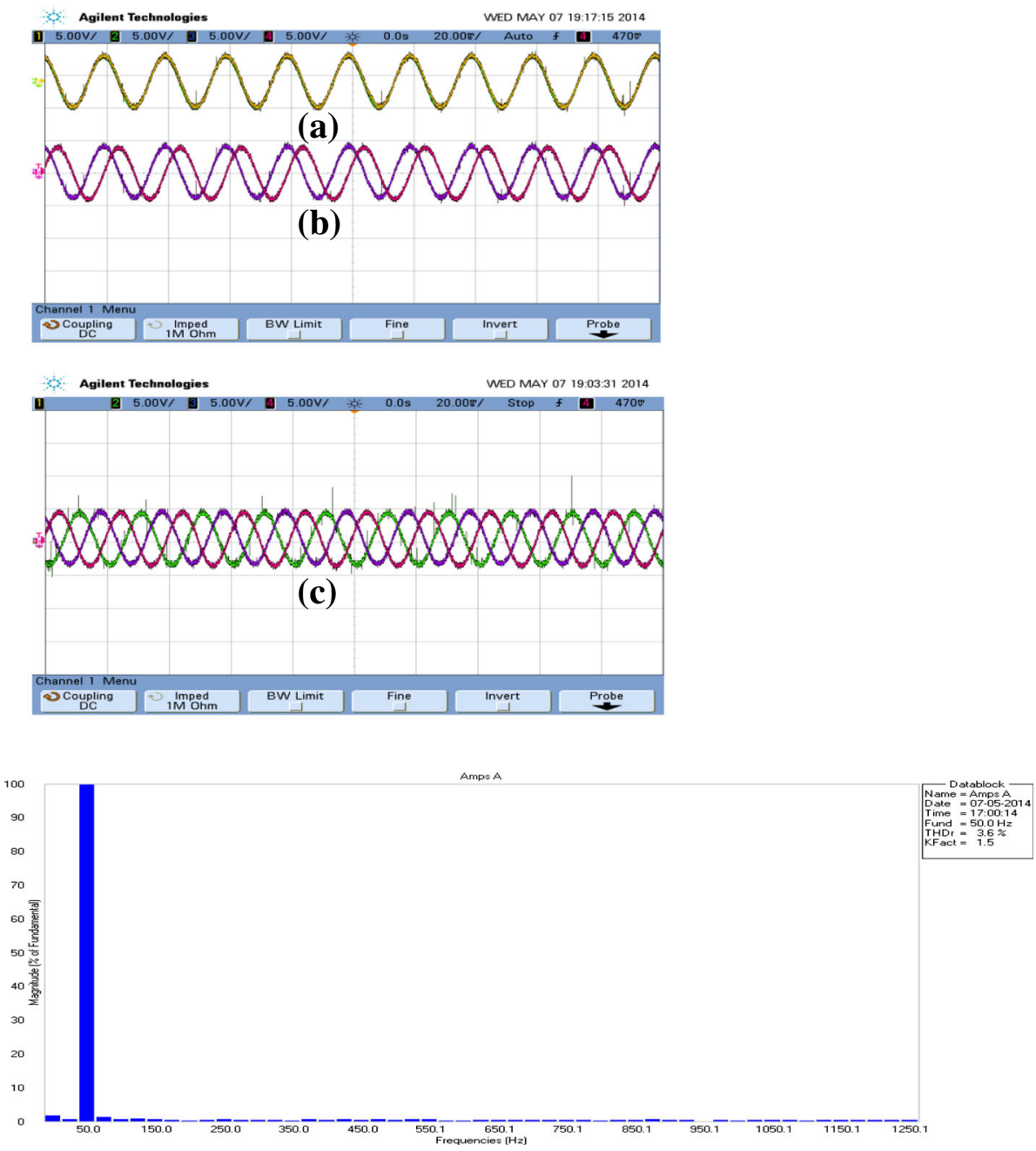

(d)

Figure 12. Experimental results of predictive current control (a) current tracking; (yellow line: load current and green line ref. current), (b) $\alpha$ (blue line)- $\beta$ (red line) components of load current, (c) three phase current and (d) spectrum analysis of the load current. 


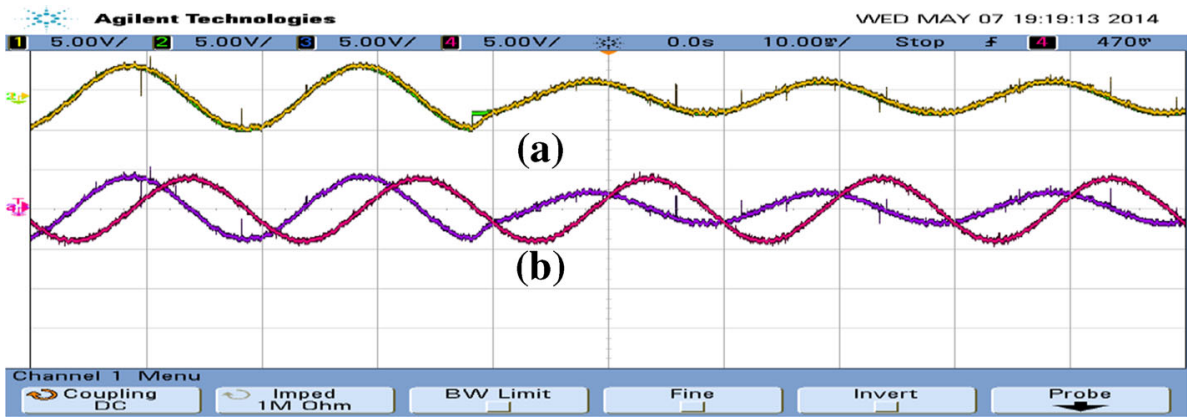

Figure 13. Response of the predicted current control technique (a) reference current tracking (reference current: green line and measured load current yellow line) and (b) $\alpha$ (blue line)- $\beta$ (red line) components of load current are decoupled from each other.

THD for the load current is $3.6 \%$ as shown in the spectral analysis of the load current in figure $12 \mathrm{~d}$.

The dynamic performance of the predictive current control is evaluated by introducing the step change in the reference current $i_{\alpha}^{r}$, while the other component $i_{\beta}^{r}$ left unchanged. The fast dynamic response is observed as load current $i_{\alpha}$ reaches its reference value in quick time as shown in figure 13a by yellow line and the $i_{\beta}$ component remains unaffected by this step change as shown in figure $13 \mathrm{~b}$ by red line. The experimental results for the PWM based current control scheme are shown in figure 14. The current MSE for PWM based method is 0.0320 . The

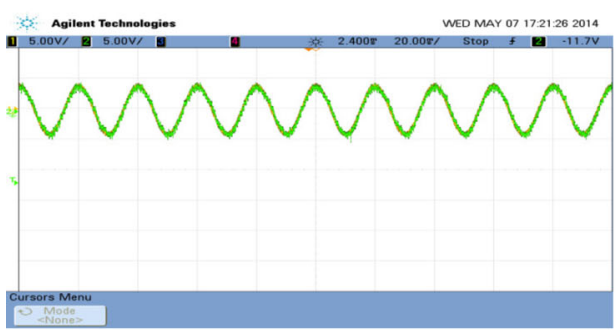

(a)

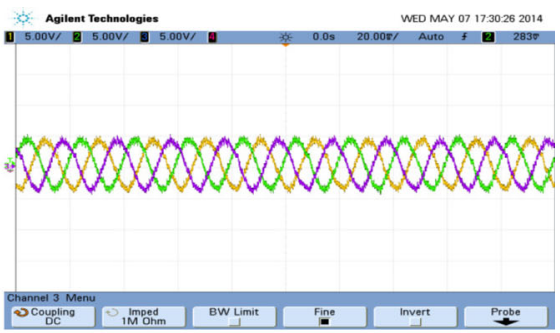

(b)

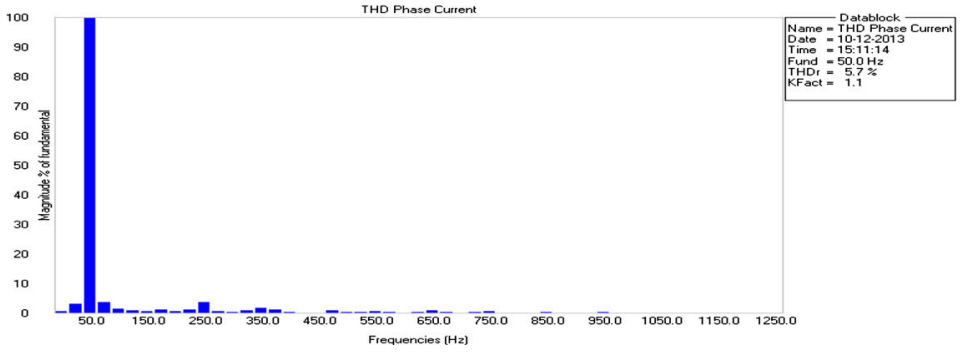

(c)

Figure 14. Experimental results of PWM based current control scheme (a) reference current tracking (ref current: yellow line and load current:green line), (b) three phase current and (c) spectrum analysis of load current. 


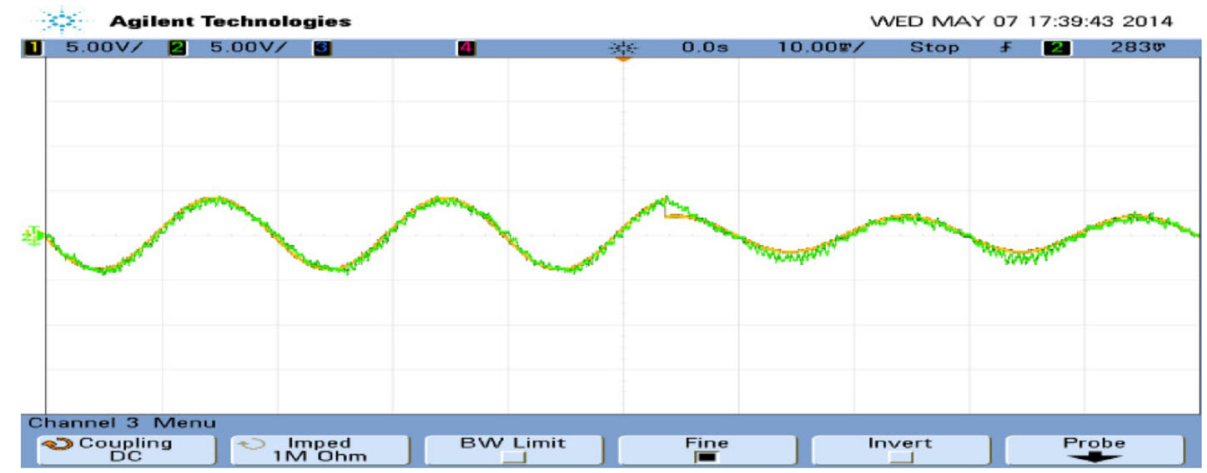

Figure 15. Results of PWM based method for reference current tracking (ref. current: yellow line and load current:green line).

spectral analysis for the for PWM based method is shown in figure 14c. The calculated THD for PWM based method is 5.7\%. The dynamic reponse of the PWM based method is shown in figure 15. The load current reaches the reference value in quick time, but tracking response is slightly slugish as compared to the predictive current control technique. The summary of the experimental results of the control schemes is shown in table 2.

For the predictive current control strategy with delay compensation and $\lambda=0$, the current MSE is 0.0051 , voltage THD is $28.7 \%$ and the load current THD is $3.67 \%$ are reduced and switching frequency got almost doubled as compared to the predictive current control strategy without delay compensation. For multiple objective optimizations with delay compensation the MSE for current tracking, THD of load voltage and load current are on the lower side for an optimized weighting factor $\lambda=0.05$. The switching frequency is reduced to 1.6 times and is almost the same as in case of PWM based method. The current MSE, load voltage THD and load current THD obtained using PWM based control scheme are higher as compared to the predictive control scheme with an optimized weighting factor. The proposed approach is slightly more computationally demanding as compared to the other implemented techniques. The average execution time calculated using dSPACE profiler for the predictive current control strategy with delay compensation is $14.21 \mu \mathrm{s}$, which is slightly higher as compared to the conventional current control technique without delay compensation which took around $10.78 \mu$ $\mathrm{s}$ to run on the same platform.

Table 2. Summary of experimental results.

\begin{tabular}{lcccccc}
\hline & \multicolumn{5}{c}{ Predictive Current Control } \\
\cline { 2 - 5 } Performance index & Without delay & \multicolumn{4}{c}{ With delay compensation } & \\
\cline { 3 - 6 } & compensation & $\lambda=0$ & $\lambda=0.01$ & $\lambda=0.05$ & $\lambda=0.1$ & PWM \\
\hline Current MSE & 0.0230 & 0.0051 & 0.0057 & 0.0088 & 0.0119 & 0.0320 \\
Voltage THD \% & 32.21 & 28.7 & 29.5 & 30.40 & 32.26 & 38.90 \\
Load current THD \% & $7.1 \%$ & 3.67 & 3.42 & 3.60 & 4.91 & 5.7 \\
Average switching frequency & $2.4 \mathrm{kHz}$ & $4.4 \mathrm{kHz}$ & $3.58 \mathrm{~Hz}$ & $2.81 \mathrm{kHz}$ & $2.1 \mathrm{kHz}$ & $\sim 2.0 \mathrm{kHz}$ \\
\hline
\end{tabular}




\section{Conclusion}

In this paper, a predictive current control strategy for multiple objective optimizations with delay compensation is analysed and implemented using dSPACE (DS-1104). It has been verified through simulations and experimental tests that by incorporating the delay in the design of the predictive current controller an improved performance in terms of tracking MSE, current and voltage THD can be obtained. Moreover, the switching frequency and the load current THD can be minimized simultaneously while the good tracking and dynamic response is maintained. The optimized weighting factor for multi-objective optimizations can be calculated using branch and bound algorithm. The results obtained using the proposed approach are better in terms of current MSE, load current and load voltage THD as compared to the PWM based method while the average switching frequency remains same for both the techniques. In comparison to the PWM based control technique the proposed control technique is simple to implement, offers fast dynamic response, flexibility to optimize multiple objectives and is free from PI controller gains tuning as required in PWM based control scheme.

\section{Appendix A}

Load parameters.

\begin{tabular}{ll}
\hline Parameter & Value \\
\hline $\mathrm{R}$ & $10 \Omega$ \\
$\mathrm{L}_{\mathrm{s}}$ & $46.3 \mathrm{mH}$ \\
$\mathrm{Vdc}$ & $300 \mathrm{~V}$ \\
$\mathrm{e}$ & $100 \mathrm{~V}$ \\
$\mathrm{I}_{\mathrm{ref}}$ & $4 \mathrm{~A}$ \\
$\mathrm{~T}_{\mathrm{s}}$ & $50 \mu \mathrm{s}$ \\
\hline
\end{tabular}

IGBT Intelligent Power Module (25A, 1200V).

\begin{tabular}{ll}
\hline Parameter & Value \\
\hline Switching frequency & $20 \mathrm{KHz}$ (Max.), 10 KHz(Nominal) \\
Braking of IGBT & $10 \mathrm{~A}, 1200 \mathrm{~V}$ (Max), $6 \mathrm{~A}$ (Nominal) \\
Maximum DC link voltage & $750 \mathrm{~V} 750 \mathrm{~V}$ \\
Fault output current & $20 \mathrm{~mA}$ (Max.) \\
Fault output voltage & $20 \mathrm{~V}$ (Max.) \\
Variable inductive load & $3 \Phi, 415 \mathrm{~V}, 0-15 \mathrm{~A}, 50 \mathrm{~Hz}$ \\
\hline
\end{tabular}

\section{References}

Abu-Rub H, Guzin ski J, Krzeminski Z and Toliyat H A 2004 Predictive current control of voltage-source inverters. IEEE Transactions on Industrial Electronics 51(3): 585-603

Bose B K 2002 Modern power electronics and AC drives, $1^{\text {st }}$ ed. New Jersey: Pearson Education Inc

Cortes P, Kouro S, La Rocca B, Vargas R, Rodriguez J, Leon J I, Vazquez S and Franquelo L G 2009 Guidelines for weighting factors design in Model Predictive Control of power converters and drives. IEEE Proc. ICIT, Gippsland, VIC 1: 1-7 
Cortes P, Rodriguez J, Silva C and Flores A 2012 Delay compensation in model predictive current control of a three-phase inverter. IEEE Transactions on Industrial Electronics 59(2): 1323-1325

Dordevic O, Jones M and Levi E 2013 A comparison of carrier-based and space vector PWM techniques for three-level five-phase voltage source inverters. IEEE Transactions on Industrial Informatics 9(2): 609-619

Fischer J R, Gonzalez S A, Herran M A, Judewicz M G and Carrica D O 2014 Calculation-delay tolerant predictive current controller for three-phase inverters. IEEE Transactions on Industrial Informatics 10(1): 233-242

Holtz J 1994 Pulse width modulation for electronic power conversion. Proc. IEEE. 82: 1194-1213

Judewicz M G, Fischer J R, Herran M A, Gonzalez S A and Carrica D O 2013 A robust model predictive control for grid-connected voltage-source inverters. IEEE Latin American Transactions 11(1): 27-33

Kouro S, Cortes P, Vargas R, Ammann U and Rodriguez J 2009 Model predictive control—a simple and powerful method to control power converters. IEEE Transactions on Industrial Electronics 56(6): 18261838

Mohan N, Undeland T M and Robbins W P 1995 Power electronics, 2nd ed. New York: Wiley

Mondal S K, Bose B K, Oleschuk V and Pinto J O P 2003 SVPWM of three level three level inverters extending operation into over modulation region. IEEE Transactions on Power Electronics 88(2): 604611

Preindl M, Schaltz E and Thogersen P 2011 Switching frequency reduction using model predictive direct current control for high-power voltage source inverters. IEEE Transactions on Industrial Electronics 58(11): 2826-2835

Rodriguez J and Cortes P 2012 Predictive control of power converters and electrical drives. New York: John Wiley \& Sons

Rodriguez J, Pontt J, Silva S A, Correa P, Lezana P and Cortes P 2007 Predictive currentcontrol of a voltage source inverter. IEEE Transactions on Industrial Electronics 54(1): 495-503

Saribulut L, Meral M E, Teke A and Tumay M 2012 Performance comparison of PWM methods for 27-level hybrid multilevel inverters. GU J. Sci. 25(3): 689-695

Shu Z, Tang J, Guo Y and Lian J 2007 An efficient SVPWM algorithm with low computational overhead for three-phase inverters. IEEE Transactions on Power Electronics 22(5): 1797-1805 